J Arid Land (2013) 5(4): 521-530

doi: $10.1007 / \mathrm{s} 40333-013-0180-0$

jal.xjegi.com; www.springer.com/40333

\title{
Estimating aboveground biomass in Mu Us Sandy Land using Landsat spectral derived vegetation indices over the past 30 years
}

\author{
Feng $\mathrm{YAN}^{1}$, Bo $\mathrm{WU}^{1 *}$, YanJiao WANG ${ }^{2}$ \\ ${ }^{1}$ Institute of Desertification Studies, Chinese Academy of Forestry, Beijing 100091, China; \\ ${ }^{2}$ National Climate Center, China Meteorological Administration, Beijing 100081, China
}

\begin{abstract}
Remote sensing is a valuable and effective tool for monitoring and estimating aboveground biomass (AGB) in large areas. The current international research on biomass estimation by remote sensing technique mainly focused on forests, grasslands and crops, with relatively few applications for desert ecosystems. In this paper, Landsat Thematic Mapper (TM)/Enhanced Thematic Mapper Plus (ETM+) images from 1988 to 2007 and the data of 283 AGB samples in August 2007 were used to estimate the AGB for Mu Us Sandy Land over the past 30 years. Moreover, temporal and spatial distribution characteristics of AGB and influencing factors of climate and underlying surface were also studied. Results show that: (1) Differences of correlations exist in the fitted equations between AGB and different vegetation indices in desert areas. The modified soil adjusted vegetation index (MSAVI) and soil adjusted vegetation index (SAVI) show relatively higher correlations with $A G B$, while the correlation between normalized difference vegetation index (NDVI) and AGB is relatively lower. Error testing shows that the AGB- MSAVI model established can be used to accurately estimate AGB of Mu Us Sandy Land in August. (2) AGB in Mu Us Sandy Land shows the fluctuant characteristics over the past 30 years, which decreased from the 1980s to the 1990s, and increased from the 1990s to 2007 . AGB in 2007 had the highest value, with a total AGB of $3.352 \times 10^{6} \mathrm{t}$. Moreover, in the 1990s, AGB had the lowest value with a total AGB of $2.328 \times 10^{6}$ t. (3) AGB with relatively higher values was mainly located in the middle and southern parts of Mu Us Sandy Land in the 1980s. AGB was low in the whole area in the1990s, and relatively higher AGB values were mainly located in the southern parts of Uxin. In 2007, $A G B$ in the whole area was relatively higher than those of the last twenty years, and higher AGB values were mainly located in the northern, western and middle parts of Mu Us Sandy Land.
\end{abstract}

Keywords: aboveground biomass (AGB); linear regression; vegetation indices; Mu Us Sandy Land

Citation: Feng YAN, Bo WU, YanJiao WANG. 2013. Estimating aboveground biomass in Mu Us Sandy Land using Landsat spectral derived vegetation indices over the past 30 years. Journal of Arid Land, 5(4): 521-530. doi: 10.1007/s40333-013-0180-0

As an important indicator of vegetation growth, biomass has been widely used for productivity evaluation and carbon cycle studies (Crow, 1978; Houghton et al., 2000; Fang et al., 2001; Burrows et al., 2003). Monitoring aboveground biomass (AGB) dynamically in desertification areas can not only show the local vegetation growth status but also provide evidences for ecosystem managers and scientists to evaluate the effects of ecological restoration in desertification areas, to study the carbon cycle and to realize the sustainable development of desert ecosystems. Mu Us Sandy Land lies on the farming-pastoral ecotone of Northern China, where a forest-grassland-desert transition zone can be found. Affected by natural and humanistic factors, Mu Us Sandy Land, whose ecological environment shows great sensitivity and vulnerability, has

*Corresponding author: Bo WU (E-mail: wubo@caf.ac.cn)

Received 2012-10-26; revised 2012-12-17; accepted 2013-02-20

(C) Xinjiang Institute of Ecology and Geography, Chinese Academy of Sciences, Science Press and Springer-Verlag Berlin Heidelberg 2013 
been considered as an important ecological barrier in China. With the implementation of the reform and opening up policy, the regional economy of Mu Us Sandy Land has rapidly developed. Accordingly, under the background of global climate change, disturbances of human activities lead to considerable variations in the spatial and temporal distribution of AGB in Mu Us Sandy Land. Studying the dynamics of AGB over the past 30 years is vital for the managers to understand the desertification process, and to comprehensively evaluate carbon stocks in $\mathrm{Mu}$ Us Sandy Land.

In the past, traditional methods for AGB estimation were mainly through sample inventory, which showed many shortcomings such as having poor representation and being time-consuming, laborious and inefficient. Remote sensing technology has macro, dynamic, economic and efficient advantages, which could make up for the inadequacies of the traditional methods. AGB estimation has been studied for many years using remote sensing reflectance and vegetation indices (Hame et al., 1997; Todd et al., 1998; Boyd et al., 1999; Huete et al., 2002; Moreaua et al., 2003; Zhang et al., 2007). Ikeda et al. (1999) used Landsat Thematic Mapper (TM) observations in 1984-1990 and climate data to estimate aboveground grassland biomass with a growth model, and revealed that TM2/TM3 was more successful than the normalized difference vegetation index (NDVI), and that the ratio TM4/TM5 had the highest performance. Curran et al. (1992) applied TM data to study the linear relationship that existed between NDVI and the leaf area index (LAI), demonstrating the potential use of Landsat TM data for studying seasonal dynamics in the forest canopy. Todd et al. (1998) used Landsat TM images to show the relationship between biomass and the tasseled cap green vegetation index (GVI), brightness index (BI), wetness index (WI), NDVI and the red waveband on grazed and ungrazed rangelands in north-central Colorado. Zheng et al. (2004) coupled AGB values in Wisconsin, USA, with various vegetation indices derived from Landsant Enhanced Thematic Mapper Plus (ETM+) data through multiple regression analysis. They found that $\mathrm{AGB}$ for pine forests was strongly related to the corrected NDVI, and that separating hardwoods from pine forests substantially improved the AGB estimations compared to those obtained with overall regression. Muukkonen and Heiskanen (2005, 2007) applied Advanced Spaceborne Thermal Emission and Reflection Radiometer (ASTER) satellite data to estimate the biomass of boreal forest stands in Finland. They put forward a method coupled with standwise forest inventory data, ASTER and Moderate Resolution Imaging Spectro-Radiometer (MODIS) satellite data to estimate biomass and verify the possibility of carbon inventories. Verbesselt et al. (2006) used Systeme Probatoire d'Observation de la Terre (SPOT) vegetation data to construct a time series in order to monitor herbaceous biomass in South Africa, and obtained a good result $\left(R^{2}=0.69\right)$. Propastin et al. (2012) chose ground biomass data and net primary production (NPP) data calculated from the sea-viewing wide field-of-view sensor (Sea WiFS) to test the reliability of their modified light use efficiency (LUE) model in the grasslands of Kazakhstan, while Claverie et al. (2012) used Formosat-2 data to simulate a time series of green area index (GAI) and dry aboveground biomass (DAM) of maize and sunflower, and their crop biomass was well estimated from the model (relative error of $28 \%$ ), especially considering that biomass measurements were not used for the calibration. According to the current international researches on biomass estimation by remote sensing techniques, we could find that they mainly focused on forests, grasslands and crops, with relatively few applications for desert ecosystems. Semi-desert and desert regions account for nearly one third of the total terrestrial area. Though a desert ecosystem has sparser vegetation than forest, grassland and crop ecosystems, its total AGB is still considerable for vast areas. Researching AGB estimation in desert ecosystems is of great significance for comprehensive evaluation of the global carbon cycle. Hence, in this paper we chose Mu Us Sandy Land, located on the farming-pastoral ecotone of Northern China, as the study area, and applied Landsat TM spectral data to model spatiotemporal variations of AGB. Furthermore, biomass dynamics over the past 30 years and influencing factors of climate and underlying surface were also analyzed, which could be used to provide scien- 
tific knowledge on desert ecosystem recovery and carbon sinks.

\section{Study area and data}

\subsection{Study area}

$\mathrm{Mu}$ Us Sandy Land is located in the northwest of China $\left(37^{\circ} 27^{\prime}-39^{\circ} 22^{\prime} \mathrm{N}, 107^{\circ} 20^{\prime}-111^{\circ} 30^{\prime} \mathrm{E}\right)$. It includes the southern part of Ejin Horo, eastern parts of Otog and Otog Qian, Uxin (Inner Mongolia autonomous region), the northern part of the sandy area in Yuyang district (Yulin city, Shaanxi province), and the northeast part of Yanchi (Ningxia Hui autonomous region), covering an area of approximately $40,000 \mathrm{~km}^{2}$ (Fig. 1). The elevation ranges from 950 to $1,600 \mathrm{~m}$, and its climate type varies from middle temperate zone to warm temperate zone. The annual mean temperature is $6.0-8.5^{\circ} \mathrm{C}$, and mean annual precipitation varies in a northwest to southeast direction from 250 to $440 \mathrm{~mm}$. Precipitation is mainly concentrated from July to September, and especially in August, which accounts for $60 \%$ to $75 \%$ of the annual precipitation. The soil types in Mu Us Sandy Land show a transitional pattern: in its northwest a semi-desert calcic brown soil zone is found, while the southwest to Yanchi is a semi-desert sierozem zone, and in its southeast is the Loess Plateau, with a warm temperate grey cinnamonic soil forest-steppe zone. Land use types are complex, and staggered distributions of different types are very common. Among all land types, agricultural land takes up the largest proportion.

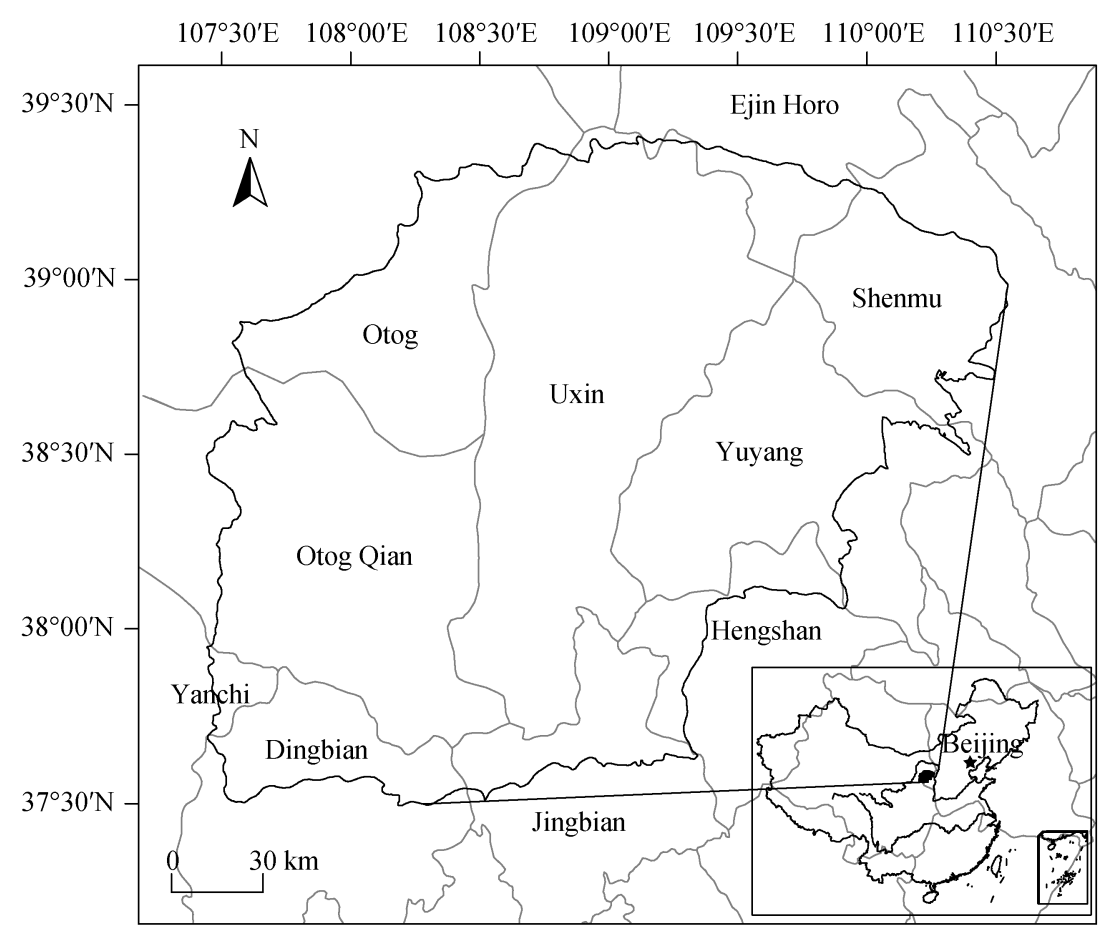

Fig. 1 Sketch map of the location of Mu Us Sandy Land

\subsection{Data}

\subsubsection{Remote sensing data}

TM/ETM+ sensors on board Landsat satellites have high spatial resolution (30-m pixel size) and a considerable data file history compared with the National Oceanic and Atmospheric Administration (NOAA) Advanced Very High Resolution (AVHRR) and Earth
Observing System (EOS)-MODIS platforms. Landsat $\mathrm{TM} / \mathrm{ETM}+$ images were used as a remote sensing data source to estimate AGB. According to the spatial extent and the best temporal periods for AGB estimation in Mu Us Sandy Land, twelve Landsat TM/ETM+ images with the path/rows 127/33, 127/34, 128/33 and 128/34 taken from 1988 to 2007 were used to represent vegetation distributions in the 1980s, 1990s and 
2007 (Table 1). Cloud free and high quality imagery was acquired mainly from August to September when vegetation was at its most flourishing period. Fast Line-of-sight Atmospheric Analysis of Spectral Hypercubes (FLAASH) atmospheric correction model was used, while mid-latitude summer and rural aerosol models were used as FLAASH specifications. After applying atmospheric correction, the digital number (DN) of the image was converted to surface reflectivity. Then, topographic maps at a scale of 1:50,000 were used to spatially locate the ground control points for geometrically correcting the satellite imagery. The map projection employed was Albers Conical Equal Area (ellipsoid is Krasovsky; longitude of central meridian is $105^{\circ} \mathrm{E}$, latitude of standard parallels are $25^{\circ} \mathrm{N}$ and $47^{\circ} \mathrm{N}$ ), and the mean error after geometric correction was controlled within 0.5 pixels.

Table 1 Landsat images chosen over the past 30 years

\begin{tabular}{|c|c|c|c|c|c|c|}
\hline Period & Sensol & Path/Rov & Acquired time & Senso & \multicolumn{2}{|c|}{ r Path/Row Acquired time } \\
\hline \multirow{2}{*}{$1980 \mathrm{~s}$} & $\mathrm{TM}$ & $127 / 33$ & 11 Sep 1989 & $\mathrm{TM}$ & $128 / 33$ & 15 Sep 1988 \\
\hline & $\mathrm{TM}$ & $127 / 34$ & 29 Aug 1990 & $\mathrm{TM}$ & $128 / 34$ & 23 Aug 1991 \\
\hline \multirow{2}{*}{$1990 \mathrm{~s}$} & ETM + & $127 / 33$ & $31 \mathrm{Jul} 2000$ & $\mathrm{ETM}+$ & $-128 / 33$ & 10 Aug 2001 \\
\hline & TM & $127 / 34$ & 01 Sep 2000 & $\mathrm{TM}$ & $128 / 34$ & 10 Aug 2001 \\
\hline \multirow{2}{*}{2007} & $\mathrm{TM}$ & $127 / 33$ & 12 Aug 2007 & $\mathrm{TM}$ & $128 / 33$ & 03 Aug 2007 \\
\hline & TM & $127 / 34$ & 12 Aug 2007 & $\mathrm{TM}$ & $128 / 34$ & 03 Aug 2007 \\
\hline
\end{tabular}

\subsubsection{AGB data}

During the last twenty days of August 2007, quadrat sampling method was carried out and 283 samples of AGB were measured in Mu Us Sandy Land. The major plant species of the study area were Artemisia ordosica, Sabina vulgaris and Tamari chinensis. Each quadrat with an area of $10 \mathrm{~m} \times 10 \mathrm{~m}$ was selected in the middle of a land type with the relative consistent characteristic, and the geographical position of the quadrat center was located by a global positioning system (GPS) receiver. Among each quadrat, three 1 $\mathrm{m} \times 1 \mathrm{~m}$ sub-quadrats were set, and plants aboveground in each sub-quadrat were cut into a sealed plastic bag. In the laboratory, plants specimens were placed in a $105^{\circ} \mathrm{C}$ oven for $30 \mathrm{~min}$ and were then dried at a constant temperature of $70^{\circ} \mathrm{C}$. The plant biomass dry weight was measured and the AGB was calculated.

\section{Methods}

\subsection{Vegetation index (VI)}

There is a relationship between the biomass amount in the ground and spectral VI, and biomass can be reflected by the VI (Tucker, 1979). VI is generally defined as mathematical transformation of surface reflectance from sensors mainly using red and near infrared spectral bands. In order to quantitatively study vegetation coverage and growth, dozens of vegetation indices have been designed. Among these indices, NDVI, Ratio Vegetation Index (RVI), Difference Vegetation Index (DVI), Soil Adjusted Vegetation Index (SAVI) and Modified Soil Adjusted Vegetation Index (MSAVI) have been commonly used (Rouse et al., 1973; Huete, 1988; Qi et al., 1994). They are as follows:

$$
\begin{aligned}
\mathrm{NDVI}= & (N I R-R E D) /(N I R+R E D), \\
\mathrm{RVI}= & N I R / R E D, \\
\mathrm{DVI}= & N I R-R E D, \\
\mathrm{SAVI}= & (1+L)[(N I R-R E D) /(N I R+R E D+L)], \\
\mathrm{MSAVI}= & \left\{2 \times N I R+1-\left[(2 \times N I R+1)^{2}-\right.\right. \\
& \left.8 \times(N I R-R E D)]^{1 / 2}\right\} / 2 .
\end{aligned}
$$

Where, NIR and RED are the reflectance of near infrared and red bands, respectively, and $L$ is a soil adjustment factor, generally using the constant $L=0.5$ (Qi et al., 1994). The reflectance values of Mu Us Sandy Land were used to calculate VI for the 1980s, 1990s and 2007.

\subsection{VI temporal standardization}

Due to the constraints of local weather conditions on satellite imaging quality, the Landsat images used in the same phase might have different radiometric data. For example, the images of the 1990s were acquired in July 2000, September 2000 and August 2001, respectively. In order to ensure radiometrical coherence and the comparability of VI in the whole area, we conducted time correction to vegetation indices retrieved at different phases. In this paper, time correction was based on the principle that the same location at the same time should have the same VI value from the same sensor with the same spatial resolution. Hence, in our study, 950 random sample points in the overlap region of two images were selected and regression method was used to establish a VI linear regression equation between the two different phases. With this 
method, all vegetation indices in different phases were corrected to the ones in the last twenty days in August. For example, in the MSAVI data in 2007, 950 random samples were selected in the overlap regions between images of $128 / 33$ and $127 / 33$ (128/34 and 127/34) to establish the two scatter plots (Fig. 2). By the fitting

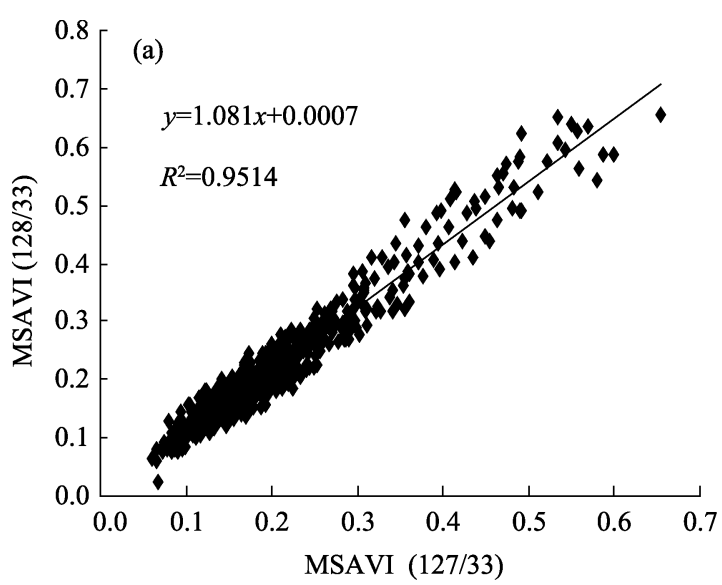

equations, MSAVI images of $128 / 33$ and $128 / 34$ acquired on 03 August 2007 were corrected to the ones acquired on 12 August 2007. By the same method, vegetation indices in the 1980s and 1990s were corrected to the ones on 29 August 1990 and 01 September 2000 , respectively.

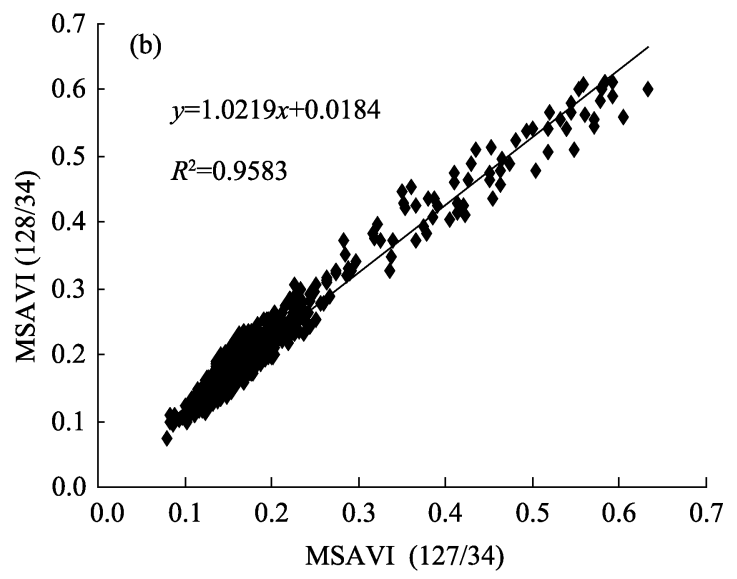

Fig. 2 Scatter plot of modified soil adjusted vegetation index (MSAVI) on 03 August and 12 August of 2007

\subsection{Relationship between AGB and VI}

\subsubsection{Correlation analysis}

Both the AGB measured in the last twenty days of August 2007 and the synchronous VI, such as MSAVI, SAVI, NDVI, RVI and DVI, were used to analyze their correlations. The results showed that there are significant correlations between AGB and VI coupled with near infrared and red spectral reflectance bands. VI can be used to estimate AGB perfectly, while different correlations existed in the fitted equations. Correlations of AGB-MSAVI and AGB-SAVI were relatively higher with the coefficients of correlation $r=0.783$ and 0.777 , respectively, which may have been caused by the adjustment of soil background when using the MSAVI and SAVI (Major et al., 1990; Qi et al., 1994). Correlations of AGB-DVI and AGB-RVI were also high with the coefficients of correlation $r=0.742$ and 0.722 , respectively. Meanwhile, the correlation of AGB-NDVI was relatively lower with the coefficients of correlation $r=0.697$. NDVI has been used most commonly to map spatial and temporal variation of vegetation (Tucker, 1979; Barnett and Thompson, 1983; Singh et al., 1992), but is affected by a background of bare soil and other factors (Huete, 1988; Huete et al., 1992; Huete et al.,
2000). Hence, NDVI is not the best VI for AGB estimation of sparse vegetation cases.

\subsubsection{Regression analysis}

In order to validate the fitted equations, 70 samples of AGB were randomly selected for validation purposes and the remaining samples (213) were used to establish the AGB-VI model (Eq. 6). Eq. 6 further shows that the coefficient of determination of AGB-MSAVI was the highest with $R^{2}=0.612$, and those of AGB-SAVI and AGB-NDVI were higher and the lowest with $R^{2}=0.604$ and 0.511 , respectively. Therefore, MSAVI can reflect distribution characteristics of AGB preferably. The corresponding vegetation indices of 70 test samples were put in Eq. 6 to calculate AGB. Mean absolute error (MAE) and mean relative error (MRE) were applied to test the reliability of the AGB estimating model of AGB-VI. The error test result showed that MAE of AGB-MSAVI model was $0.115 \mathrm{t} / \mathrm{hm}^{2}$ and MRE was $15.63 \%$; MAE of AGB-SAVI model was $0.136 \mathrm{t} / \mathrm{hm}^{2}$ and MRE was $18.48 \%$; MAE of AGB-NDVI model was $0.217 \mathrm{t} / \mathrm{hm}^{2}$ and MRE was $27.64 \%$. The AGB-MSAVI model established could fully estimate the AGB of Mu Us Sandy Land in August.

$$
A G B=12.733 \times M S A V I-1.315\left(R^{2}=0.612\right),
$$


$A G B=11.604 \times S A V I-1.3267\left(R^{2}=0.604\right), \quad(6 \mathrm{~b}) \quad$ were used to calculate AGB in Mu Us Sandy Land $A G B=5.5628 \times N D V I-0.6326\left(R^{2}=0.511\right) . \quad(6 \mathrm{c}) \quad$ over the past 30 years. A land use and land cover map

\section{Results and discussion}

\subsection{Spatial and temporal distribution characteris-} tics of AGB

MSAVI data taken for the 1980s, 1990s and 2007 made from maximum likelihood classification was used to mask water bodies, farmland and urban areas. Finally, and by Boolean extraction, AGB maps of Mu Us Sandy Land for the 1980s, 1990s and 2007 were obtained (Figs. 3-5).

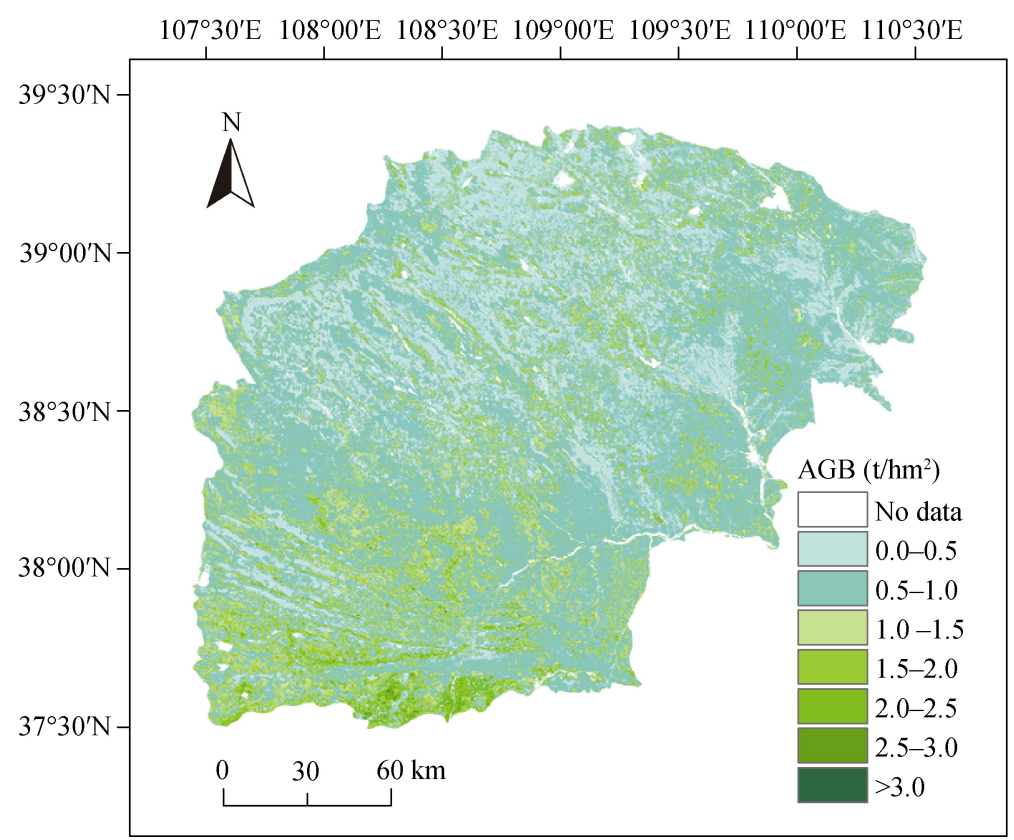

Fig. 3 Distributions of aboveground biomass (AGB) in Mu Us Sandy Land in the 1980s

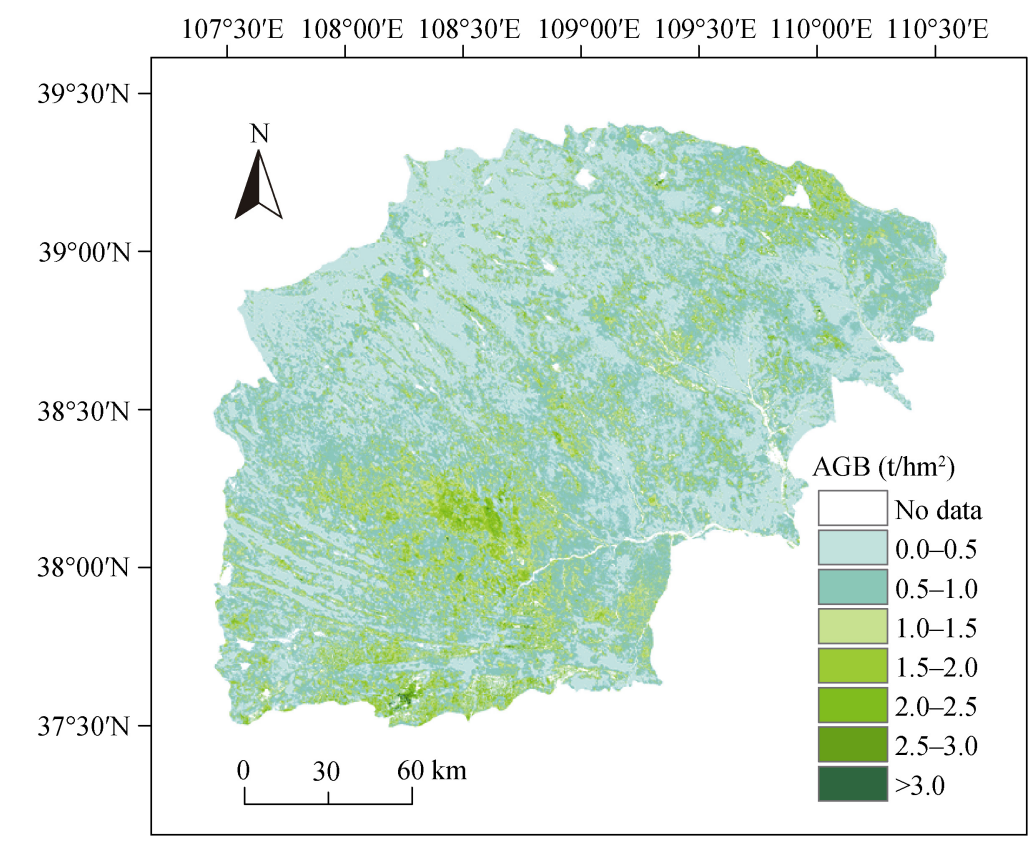

Fig. 4 Distributions of aboveground biomass (AGB) in Mu Us Sandy Land in the 1990s 


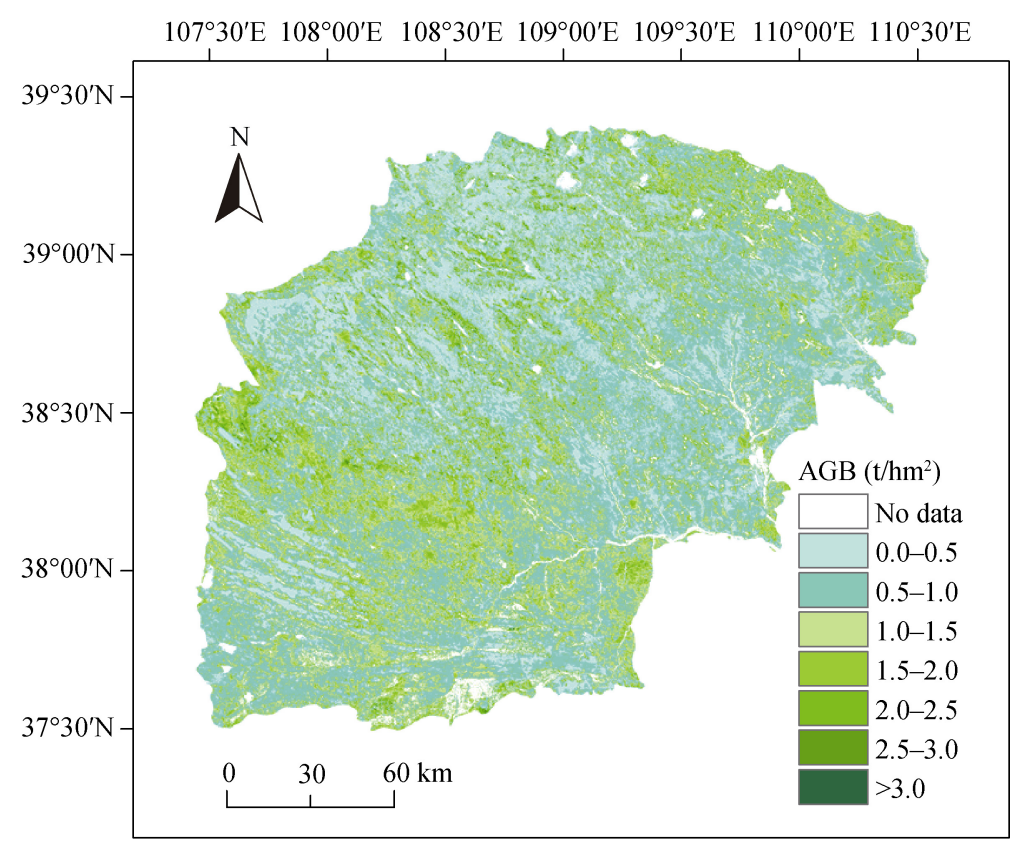

Fig. 5 Distributions of aboveground biomass (AGB) in Mu Us Sandy Land in 2007

By analyzing the AGB statistical results for the 1980s, 1990s and 2007 in Mu Us Sandy Land (Table 2), we can find that both the total AGB and average AGB are fluctuated dynamically. Over the past 30 years, AGB in 2007 had the highest value with a total AGB of $3.352 \times 10^{6} \mathrm{t}$ and a mean AGB of $0.933 \mathrm{t} / \mathrm{hm}^{2}$. AGB in the 1990s had the lowest value, with a total AGB of $2.328 \times 10^{6} \mathrm{t}$ and a mean AGB of $0.642 \mathrm{t} / \mathrm{hm}^{2}$. AGB in Mu Us Sandy Land decreased from the 1980s to 1990s and then increased from the 1990s to 2007. Over the past 30 years, AGB distributions showed obvious variation. In the 1980 s, regions with higher AGB values $\left(>1.500 \mathrm{t} / \mathrm{hm}^{2}\right)$ were mainly distributed in the southern part of Uxin and northern part of Jingbian; in the 1990s, the southern part of Uxin had higher AGB values; while in 2007, AGB values in the whole $\mathrm{Mu}$ Us Sandy Land were relatively higher than those of the last twenty years. AGB with higher values in 2007 was mainly distributed in the eastern part of Otog, southern and middle parts of Uxin, southern part of Ejin Horo and northwest part of Hengshan.

Table 2 Aboveground biomass (AGB) in Mu Us Sandy Land over the past 30 years

\begin{tabular}{ccc}
\hline Period & Total AGB $\left(\times 10^{6} \mathrm{t}\right)$ & Average AGB $\left(\mathrm{t} / \mathrm{hm}^{2}\right)$ \\
\hline $1980 \mathrm{~s}$ & 2.968 & 0.805 \\
$1990 \mathrm{~s}$ & 2.328 & 0.642 \\
2007 & 3.352 & 0.933 \\
\hline
\end{tabular}

\subsection{Causes of AGB distribution variation}

\subsubsection{Meteorological factors}

During the process of vegetation growth, water and heat are the most important factors. The Uxin region, located in the hinterland of Mu Us Sandy Land, is a representative area where spatiotemporal patterns of temperature and precipitation can explain a greater extent. A time lag exists between vegetation growth and meteorological factors (Schmidt and Karnieli, 2000; Roerink et al., 2003; Nezlina et al., 2005), and so in this paper, we considered such a time lag when monitoring AGB; thus the precipitation data of the previous year were taken into account. Analyzing the changes of total AGB and precipitation of the previous year from the 1980s to 2007 (Fig. 6), we can find that a consistent trend exists between the two parameters. In the $1980 \mathrm{~s}$ and $1990 \mathrm{~s}$, the values of total AGB were $2.968 \times 10^{6} \mathrm{t}$ and $2.328 \times 10^{6} \mathrm{t}$, respectively, and the precipitation of the previous year was $354.7 \mathrm{~mm}$ and $164.3 \mathrm{~mm}$, respectively. With the decrease in precipitation of the previous year, total AGB reduced accordingly from the 1980s to 1990s. In 2007, total AGB and precipitation of the previous year were $3.352 \times 10^{6} \mathrm{t}$ and $320.3 \mathrm{~mm}$, respectively. From the 1990s to 2007, with the increase of precipitation in the previous year, total AGB also showed an increasing trend. 


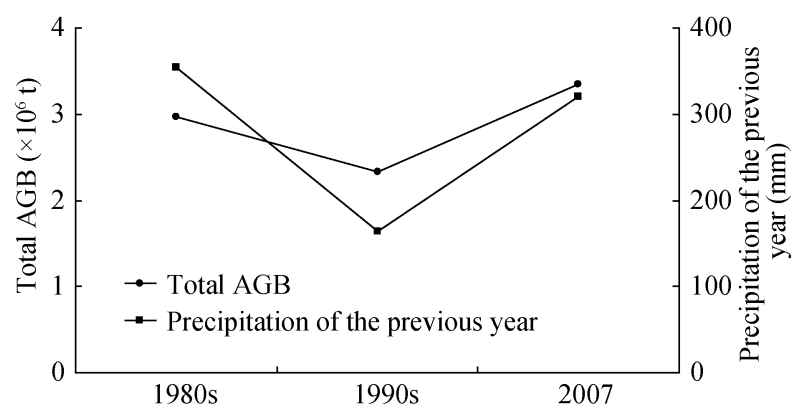

Fig. 6 Changes of total aboveground biomass (AGB) and precipitation of the previous year in Mu Us Sandy Land from the 1980s to 2007

Through analyzing the changes of annual precipitation and annual average temperature in $\mathrm{Mu}$ Us Sandy Land from 1960 to 2010 (Fig. 7), we can find both temperature and precipitation fluctuated over a 50-year period. The annual average temperature shows a gradually increasing trend with an average speed of $0.0483^{\circ} \mathrm{C} / \mathrm{a}$. In the $1980 \mathrm{~s}, 1990 \mathrm{~s}$ and 2007 , the values of annual average temperature were $7.95^{\circ} \mathrm{C}$, $8.05^{\circ} \mathrm{C}$ and $8.90^{\circ} \mathrm{C}$, respectively. In the $1980 \mathrm{~s}$ and 2007, affected by higher annual precipitation, both total and average AGB values of Mu Us Sandy Land were relatively higher. On the contrary, the annual precipitation was clearly lower in the 1990s than in the other two phases, while annual average temperature was relatively higher. For example, the precipitation of 2000 and 1999 was $178.8 \mathrm{~mm}$ and $164.3 \mathrm{~mm}$, respectively, $47.61 \%$ and $51.86 \%$ lower than the average level. Continuous severe droughts occurred from 1999 to 2000, which had a negative effect on the growth of natural vegetation to a certain extent and should be the most important reason for the existence of significantly lower AGB in the 1990s than in the 1980s and 2007. By analyzing annual precipitation and annual average temperature in the 1980s and 2007 in Mu Us Sandy Land, we found that a great difference existed between the total and average AGB, in spite of a considerable level that existed in meteorological factors in the two phases. Hence, meteorological factors such as temperature and precipitation were primary factors affecting desertification, but not the only ones. Changes in the underlying surface controlled by humanistic activities should be another important factor.

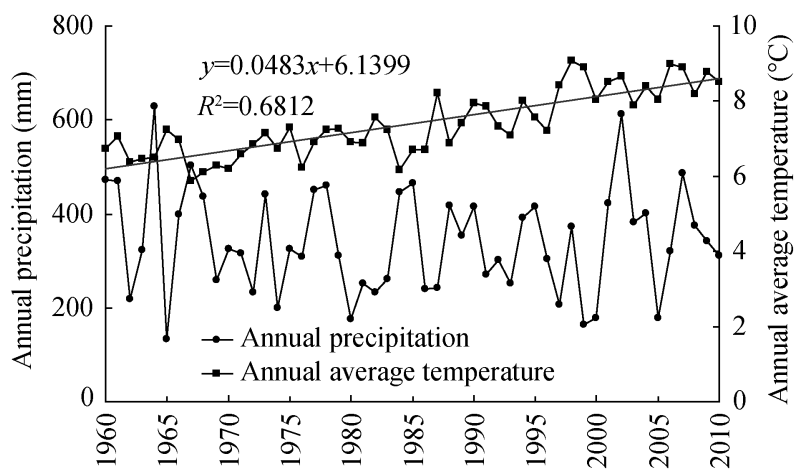

Fig. 7 Distribution of annual precipitation and annual average temperature in Mu Us Sandy Land from 1960 to 2010

\subsubsection{Underlying surface factors}

Changes of AGB in Mu Us Sandy Land are affected not only by meteorological factors such as precipitation and temperature, but also by manners of production and the lifestyle of the population. Furthermore, national and regional policy interventions and interest-driven impacts are also important factors for underlying land use changes. For example, in 1978 the Chinese government implemented the Three-North Shelterbelt Project, which played a key role in promoting afforestation in Mu Us Sandy Land. Then, with the implementation of the policy of allocating pasture to smallholdings, the phenomena of over-cultivation, over-cutting and over-grazing were controlled. Moreover, two policies of limiting the effects of goat grazing, the Grain for Green Project implemented in 1999 and the Aerial Seeding Afforestation Project implemented in Mu Us Sandy Land, had significant impacts on combating desertification and promoting vegetation recovery. Variations of AGB affected by desertification can be reflected by land changes of different types of underlying surface. Interpretation was done to Landsat TM imagery of Mu Us Sandy Land over the past 30 years, and the regions of water bodies, cropland and urban areas were masked. Thus, statistics of land cover change in Mu Us Sandy Land over the past 30 years were estimated (Table 3 ). From the 1980 s to 2007 , drifting sandy land area was the largest in the 1990s and the smallest in 2007; the semi-fixed sandy land area was the largest in 2007 and the smallest in the 1990s; while fixed sandy land area was the largest in the 1980s and the smallest in the 1990s. Among the three phases, the area of drifting 
sandy land in the 1990s was the largest while those of fixed and semi-fixed sandy land with a sum of $17,470.8 \mathrm{~km}^{2}$ were the smallest. That the most serious desertification in the 1990s is an important reason why it resulted in the lowest AGB. On the other hand, the area of drifting sandy land in 2007 was the smallest while the total area of fixed and semi-fixed sandy land was the largest at $21,788.5 \mathrm{~km}^{2}$ among the three phases. Desertification in 2007 was relatively the weakest, which resulted in the highest AGB. In the 1980 s, the area of drifting sandy land was relatively higher, while the total area of fixed and semi-fixed sandy land was also higher at a value of 20,373.8 $\mathrm{km}^{2}$, which resulted in higher AGB in the 1980s, accordingly.

Table 3 Land cover change in Mu Us Sandy Land over the past 30 years

\begin{tabular}{llll}
\hline \multirow{2}{*}{ Period } & Drifting sandy land & Semi-fixed sandy land & Fixed sandy land \\
\cline { 2 - 4 } & \multicolumn{3}{c}{$\left(\mathrm{km}^{2}\right)$} \\
\hline $1980 \mathrm{~s}$ & $16,462.8$ & $12,116.0$ & $8,257.8$ \\
$1990 \mathrm{~s}$ & $18,811.5$ & $10,767.9$ & $6,702.9$ \\
2007 & $14,129.3$ & $14,619.6$ & $7,168.9$ \\
\hline
\end{tabular}

\section{Conclusions}

AGB can be used as an important spatiotemporal indicator of desertification. In this paper, Landsat TM/ETM+ imagery from the 1980s to 2007 and in situ AGB data were coupled to estimate AGB in $\mathrm{Mu}$ Us Sandy Land over the past 30 years. Besides, both meteorological and underlying surface data in different phases were used to explain the cause of spatiotemporal distribution of AGB. We have primarily drawn the following conclusions:

(1) Low correlation of AGB-NDVI was obtained. While correlations of AGB-MSAVI and AGB-SAVI were relatively higher and were most adequate to estimate AGB in a desert region with sparse vegetation and bare ground.

(2) MAE and MRE were applied to test the reliability of the AGB estimation model of AGB-VI. Errors test found that the AGB-MSAVI has the smallest MAE and MRE among the AGB-MSAVI, AGB-SAVI and AGB-NDVI models. The AGB-MSAVI model could estimate AGB in August in Mu Us Sandy Land effectively.

(3) AGB in Mu Us Sandy Land fluctuated dynamically over the past 30 years, decreasing from the 1980s to 1990s and increasing from the 1990s to 2007. AGB in 2007 had the highest value, with a total AGB of $3.352 \times 10^{6} \mathrm{t}$ and a mean AGB of $0.933 \mathrm{t} / \mathrm{hm}^{2}$. Moreover, in the 1990s, AGB had the lowest value with a total AGB of $2.328 \times 10^{6} \mathrm{t}$ and a mean AGB of $0.642 \mathrm{t} / \mathrm{hm}^{2}$.

(4) AGB denser areas were mainly found in the middle and southern parts of the study area in the 1980s. AGB was low in all areas in the 1990s, and relatively higher AGB values were located in the southern parts of Uxin. In 2007, AGB was relatively higher in all areas, and higher AGB values were mainly located in the northern, western and middle parts of Mu Us Sandy Land.

\section{Acknowledgements}

This research was funded by the National Nonprofit Institute Research Grant of Chinese Academy of Forestry (CAFYBB2011003, CAFYBB2011002), the Key Laboratory of Agrometeorological Support and Applied Technique of China Meteorological Administration (AMF201107, AMF201204), and the National Natural Science Foundation of China (40801173).

\section{References}

Barnett J L, Thompson D R. 1983. Large area relation of Landsat MSS and NOAA-6 AVHRR spectral data to wheat yield. Remote Sensing of Environment, 13(4): 277-290.

Boyd D S, Foody G M, Curran P J. 1999. The relationship between the biomass of Cameroonian tropical forests and radiation reflected in middle infrared wavelengths $(3.0-5.0 \mu \mathrm{m})$. International Journal of Remote Sensing, 20(5): 1017-1023.

Burrows S N, Gower S T, Norman J M, et al. 2003. Spatial variability of aboveground net primary production for a forested landscape in northern Wisconsin. Canadian Journal of Forest Research, 33(10): 2007-2018.

Claverie M, Demarez V, Duchemin B, et al. 2012. Maize and sunflower biomass estimation in southwest France using high spatial and temporal resolution remote sensing data. Remote Sensing of Environment, 124: 844-857.

Crow T R. 1978. Biomass and production in three contiguous forests in northern Wisconsin. Ecology, 59(2): 265-273.

Curran P J, Dungan J L, Gholz H L. 1992. Seasonal LAI in slash pine estimated with landsat TM. Remote Sensing of Environment, 39(1): 
3-13.

Fang J Y, Chen A P, Peng C H, et a1. 2001. Changes in forest biomass carbon storage in China between 1949 and 1998. Science, 292(5525): 2320-2322.

Hame T, Salli A, Andersson K, et al. 1997. A new methodology for the estimation of biomass of conifer dominated boreal forest using NOAA AVHRR data. International Journal of Remote Sensing, 18(15): 3211-3243.

Houghton R A, Skole D L, Nobre C A, et al. 2000. Annual fluxes of carbon from deforestation and regrowth in the Brazilian Amazon. Nature, 403: 301-304.

Huete A, Didan K, Shimabokuro Y, et al. 2000. Regional Amazon Basin and global analysis of MODIS vegetation indices: early results and comparisons with AVHRR. Proceeding of IGARSS, 6(2): 536-538.

Huete A, Didan K, Miura T, et al. 2002. Overview of the radiometric and biophysical performance of the MODIS vegetation indices. Remote Sensing of Environment, 83(1-2): 195-213.

Huete A R. 1988. A soil adjusted vegetation index (SAVI). Remote Sensing of Environment, 25(3): 295-309.

Huete A R, Hua G, Qi J, et al. 1992. Normalization of multidirectional red and NIR reflectances with the SAVI. Remote Sensing of Environment, 41(2-3): 143-154.

Ikeda H, Okamoto K, Fukuhara M. 1999. Estimation of aboveground grassland phytomass with a growth model using Landsat TM and climate data. International Journal of Remote Sensing, 20(11): 2283-2294.

Major D J, Baret F, Guyot G. 1990. A ratio vegetation index adjusted for soil brightness. International Journal of Remote Sensing, 11(5): $727-740$.

Moreaua S, Bossenob R, Gu X F, et al. 2003. Assessing the biomass dynamics of Andean bofedal and totora high-protein wetland grasses from NOAA/AVHRR. Remote Sensing of Environment, 85(4): 516-529.

Muukkonen P, Heiskanen J. 2005. Estimating biomass for boreal forests using ASTER satellite data combined with standwise forest inventory data. Remote Sensing of Environment, 99(4): 434-447.

Muukkonen P, Heiskanen J. 2007. Biomass estimation over a large area based on standwise forest inventory data and ASTER and MODIS satellite data: a possibility to verify carbon inventories. Remote Sensing of Environment, 107(4): 617-624.

Nezlina N P, Kostianoyb A G, Li B L. 2005. Inter-annual variability and interaction of remote-sensed vegetation index and atmospheric precipitation in the Aral Sea region. Journal of Arid Environments, 62(4): 677-700.

Propastin P A, Kappas M W, Herrmann S M, et al. 2012. Modified light use efficiency model for assessment of carbon sequestration in grasslands of Kazakhstan: combining ground biomass data and remote-sensing. International Journal of Remote Sensing, 33(5-6): 1465-1487.

Qi J, Chehbouni A, Huete A R. 1994. A modified soil adjusted vegetation index. Remote Sensing of Environment, 48(2): 119-126.

Roerink G J, Menenti M, Soepboer W, et al. 2003. Assessment of climate impact on vegetation dynamics by using remote sensing. Physics and Chemistry of the Earth, 28(1-3): 103-109.

Rouse J W, Haas R H, Schell J A, et al. 1973. Monitoring vegetation systems in the Great Plains with ERTS. In: Freden S C, Mercanti E P, Becker M. Third Earth Resources Technology Satellite-1 Symposium. Technical Presentations, Section A, Vol. I. Washington, DC: National Aeronautics and Space Administration, 309-317.

Schmidt H, Karnileli A. 2000. Remote sensing of the seasonal variability of vegetation in a semi-arid environment. Journal of Arid Environments, 45(1): 43-59.

Singh R, Goyal R C, Saha S K, et al. 1992. Use of satellite spectral data in crop yield estimation surveys. International Journal of Remote Sensing, 13(14): 2583-2592.

Todd S W, Hoffer R M, Milchunas D G. 1998. Biomass estimation on grazed and ungrazed rangelands using spectral indices. International Journal of Remote Sensing, 19(3): 427-438.

Tucker C J. 1979. Red and photographic infrared linear combinations for monitoring vegetation. Remote Sensing of Environment, 8(2): $127-150$.

Verbesselt J, Somers B, van Aardt J, et al. 2006. Monitoring herbaceous biomass and water content with SPOT VEGETATION time-series to improve fire risk assessment in savanna ecosystems. Remote Sensing of Environment, 101(3): 399-414.

Zhang L, Wylie B, Loveland T, et a1. 2007. Evaluation and comparison of gross primary production estimates for the Northern Great Plains grasslands. Remote Sensing of Environment, 106(2): 173-189.

Zheng D L, Rademacher J, Chen J Q, et al. 2004. Estimating aboveground biomass using Landsat 7 ETM+ data across a managed landscape in northern Wisconsin, USA. Remote Sensing of Environment, 93(3): 402-411. 